\title{
Analisis Sifat Batuan Karbonat untuk Evaluasi Bahan Timbunan
}

\author{
Maulana Hutama Rahma Putra, Widya Utama, dan Firman Syaifuddin \\ Departemen Teknik Geofisika,Institut Teknologi Sepuluh Nopember (ITS) \\ e-mail:widya@geofisika.its.ac.id
}

\begin{abstract}
Abstrak-Faktor yang memengaruhi strategi dan proses pembangunan infrastruktur adalah jenis lapisan tanah pada wilayah pembangunan. Lapisan tanah yang didominasi lempung, yang memiliki nilai faktor keamanan kecil, tidak aman untuk dibangun infrastruktur. Faktor keamanan pada tanah itu dapat ditingkatkan dengan cara konsolidasi berupa penimbunan bahan timbunan. Tetapi dengan adanya perlakuan tersebut akan menyebabkan penurunan tanah (Settlement). Sehingga penilitian ini bertujuan untuk klasifikasi parameter fisis batuan Karbonat yang digunakan sebagai bahan penimbun tersebut serta pengaruhnya terhadap penurunan tanah. Dengan mengetahui distribusi setiap parameter fisisnya seperti densitas, porositas, kompresibilitas dan resistivitas, jenis batuan dapat diklasifikasikan menjadi beberapa kelas. Metode klasifikasi yang digunakan adalah Gaussian Mean Mixture dimana pada hasilnya memberikan klasifikasi optimal dengan jumlah 2 jenis. Hasil klasifikasi berdasarkan nilai kompresibilitasnya adalah $1.0526 \times 10^{-7}$ per pascal dan $2.484 \times 10^{-7}$ per pascal. Sedangkan dari pemodelan menggunakan batuan yang diklasifikasikan, didapatkan bahwa pencampuran kedua jenis batuan memberikan kualitas timbunan yang baik dimana memberikan konsolidasi $100 \%$ dengan penurunan tanah sebesar $138.4 \mathrm{~mm}$.
\end{abstract}

Kata Kunci-Batuan Karbonat, Gaussian Mean Mixture, Parameter Fisis, Settlement

\section{PENDAHULUAN}

$\mathrm{F}_{\mathrm{p}}$ AKTOR yang memengaruhi strategi dan proses pembangunan infrastruktur adalah jenis lapisan tanah pada wilayah pembangunan. Wilayah, seperti Surabaya atau Gresik, merupakan target pembangunan infrastruktur dimana secara geologi memiliki lapisan dangkal yang didominasi oleh Lempung (Shale) [1]. Lapisan yang didominasi oleh lempung tidak aman apabila dilakukan pembangunan langsung diatasnya dikarenakan kecilnya faktor keamanan dari lempung [2]. Solusi yang dapat dilakukan adalah menimbun lapisan lempung dengan batuan karbonat sampai dengan elevasi yang ditentukan. Dengan dilakukannya penimbunan maka diharapkan pembangunan infrastuktur dapat meningkatkan faktor keamaan pada wilayah tersebut.

Proses penimbunan lapisan lunak oleh karbonat tidak serta merta hanya menimbun diatasnya, tetapi juga dilakukan pengompakan lapisan agar menjadi lebih padat. Setelah dilakukan pengompaksian, tentu terjadi perubahan ukuran yang mengakibatkan perubahan volume [3]. Perubahan volume awal hingga setelah pemadatan dapat dihitung dengan mengetahui paramter fisik batuannya. Dari parameter fisis yang telah didapatkan, maka batuan dapat dikelompokan berdasarkan parameternya. Pengelompokan ini bertujuan untuk menentukan batuan mana yang lebih baik digunakan dalam melakukan proses timbunan. Oleh karena itu, penelitian yang dilakukan adalah analisis parameter fisis pada batuan karbonat yang bertujuan untuk mengetahui bagaimana
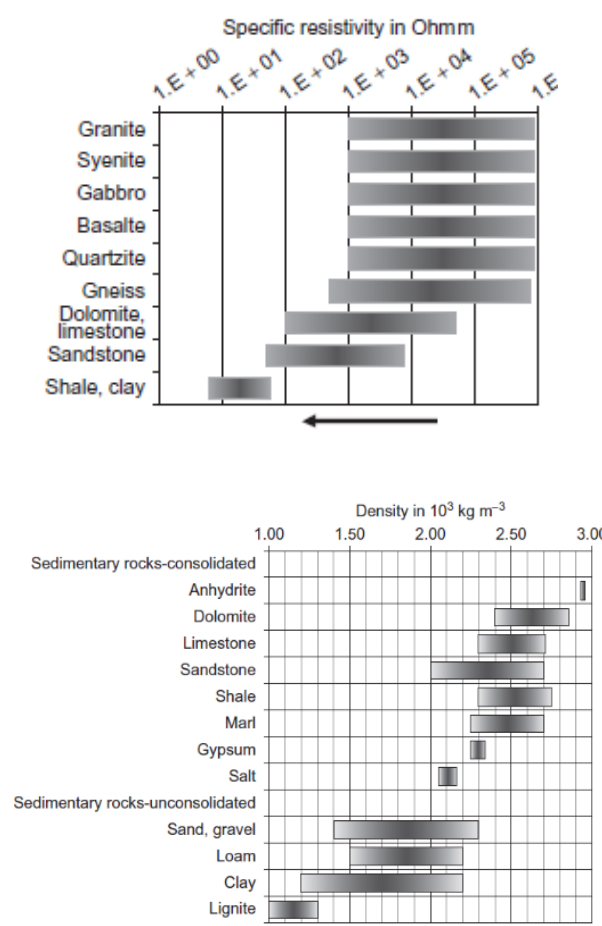

Gambar 1. Jenjang Resistivitas Batuan (Tanda panah menandakan pori dan retakan diisi oleh air)

karakteristik dari batuan serta melakukan pengklasifikasiannya menggunakan Gaussian Mean Mixture untuk bahan timbunanan yang akan digunakan serta berapa penurunan tanah pada lokasi penilitian ketika dilakukan penimbunan menggunakan bahan tersebut.

\section{DASAR TEORI}

\section{A. Karakteristik Batuan Karbonat}

Klasifikasi batuan sedimen dibagi beberapa jenis, salah satunya adalah batuan karbonat yang memiliki ciri khusus. Dibagi menjadi dua yaitu gamping (kaya akan kalsit) dan dolomit (gamping yang terjadi dolomisasi). Pada dasarnya, pembentukan sedimen melalui proses sedimentasi seperti erosi, transportasi dan deposit. Sedangkan untuk batuan karbonat, terbentuk disebabkan oleh proses biologi dimana yang memengaruhi besarnya butir akibat dari kecepatan arus laut yang membawa bahan kalsit dan proses tersebut yang menjadi penentu karakterstik dari batuan karbonat tersebut. Secara sifat fisis, batuan karbonat memiliki nilai resistivitas yang sangat beragam [4]. Hal ini dikarenakan pengisi rongga serta mineral sebagai butir dalam batuan karbonat sendiri bergantung pada proses biologi. Pada Gambar 1. merupakan jenjang nilai resistivitas yang dimiliki oleh batuan dimana memiliki jenjang yang sangat besar diakibatkan dari material 


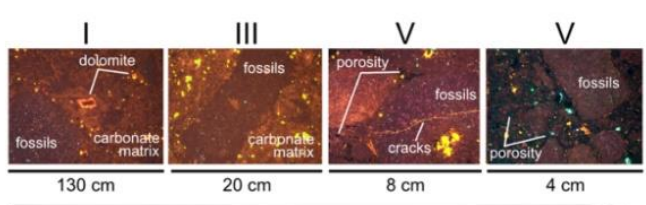

Weathering intensity $\not$

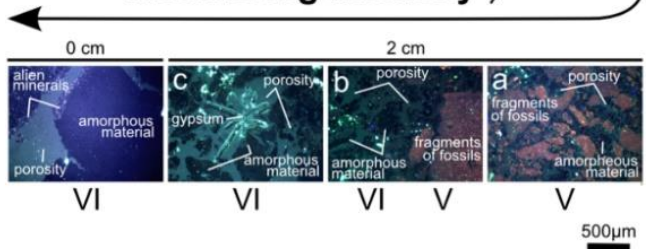

Gambar 1. Contoh sayatan tipis batu karbonat terhadap kondisi pelapukan
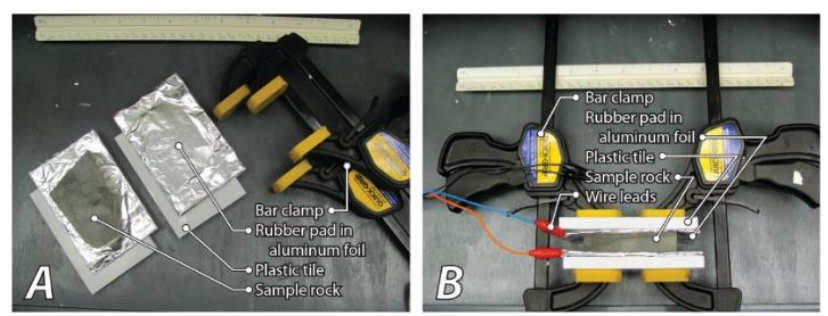

Gambar 3. Uji Laboratorium Resistivitas Sampel

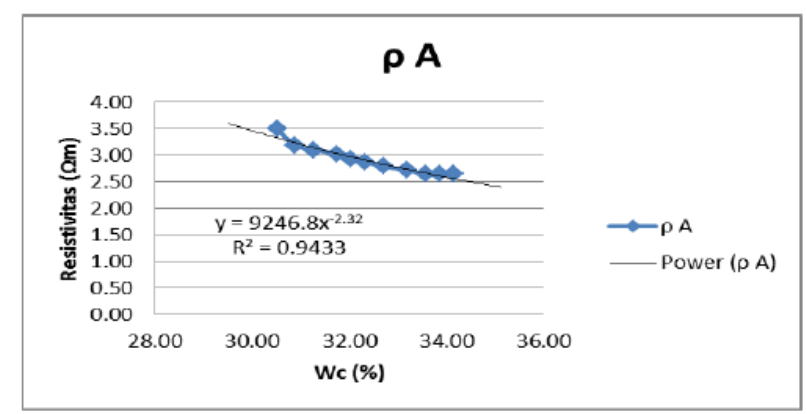

Gambar 4. Contoh Kurva hubungan antara Resistivitas-Water Content

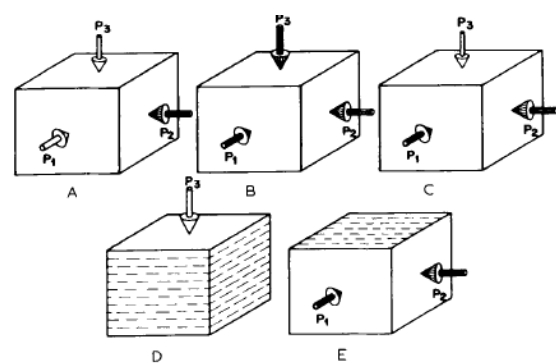

Gambar 5. Uji Laboratorium Kompresbilitas (A) Polyaxial Loading, (B) Hydrostatic Loading, (C) Triaxial Loading, (D) Uniaxial Loading, (E) Biaxial Loading.

pengisi fluida serta beragam mineral pembentuk.

Adapun karakter selain resistivitas adalah densitas batuan. Dimana densitas batuan karbonat memiliki jenjang densitas $2.3-2.7 \mathrm{gram} / \mathrm{cm}^{3}$. Densitas suatu batuan sangat bergantung terhadap beberapa aspek seperti butiran pembentuk batuan, besarnya porositas dan fluida pengisi. Sehingga untuk densitas batuan (bulk density) dinyatakan dengan densitas matriks $\left(\rho_{m a}\right)$, densitas fluida $\left(\rho_{f l}\right)$ dan persentase pori pada batuan $(\varnothing)[4]$.

$$
\rho_{\text {bulk }}=\rho_{m a} * \varnothing+\rho_{f l} *(1-\varnothing)
$$

Klasifikasi dari batu gamping tidak hanya dari jenisnya saja yaitu, dolomite dan Limestone. Tetapi ada klasifikasi terkait tingkat kelapukan dari batuan karbonat berdasarkan analisa sayatan [5]. Batu karbonat yang memiliki kelapukan yang tinggi ditandai oleh persentase Carbonate Rock
Weathering (CRW) yang berkaitan dengan densitas dan porositasnya serta dihitung berdasarkan berkurangnya kandungan Kalsit pada batuan Karbonat,

$$
C R W=1-\frac{M_{1}^{i}}{M_{1}^{f}}
$$

Dimana $\mathrm{M}_{1}$ menandakan jumlah massa dari Kalsit dari batuan karbonat, sedangkan i menandakan kondisi lapukan saat ke - i dan f merupakan kondisi saat segar (fresh). Sehingga semakin tinggi persentase dari CRW akan memberikan kondisi porositas yang semakin besar dan densitas yang semakin kecil. Contoh dari sayatan tipis terhadap klasifikasi CRW dapat dilihat pada Gambar 2.

\section{B. Parametetr Fisis Batuan}

Fisika batuan merupakan studi yang bertujuan mengkarakterisasikan sifat batua. Fisika batuan menyediakan koneksi antara sifat elastik yang diukur pada lapisan bumi. Dalam lingkungan lubang bor dan laboratorium, hal yang dapat dipelajari melalui fisika batuan ada mineralogi, porositas, bentuk pori, fluida pori, tekanan pori, permeabilitas, viskosits, tegasan, laminsi, dan rekahan. Fisika batuan menyediakan pemahaman serta alat bantu untuk mendapat gambaran dan solusi karakterisasi berdasarkan data elastic [5].

\section{1) Resistivitas}

Uji resistivitas dapat dilakukan dalam skala lab seperti penelitian yang telah dilakukan oleh Arsyadi dengan hasil seperti pada Gambar 4 [6]. Penelitian yang bertujuan untuk mengetahui pengaruh fluida pada resistivitas sampel tanah memberikan gambaran bagaimana cara melakukan uji resistivitas dalam skala laboratorium. Sedangkan untuk alat pengujian yang digunakan dalam pengukuran resistivitas dalam skala lab adalah LCR meter. Namun, untuk pengukuran yang dilakukan pada penelitian ini menggunakan multimeter [7]. Uji Laboratorium resistivitas sampel dapat dilihat pada Gambar 3.

\section{2) Kompresibilitas}

Ketika tekanan hidrostatik diberikan ke suatu batuan atau bahan, maka akan terjadi suatu perbedaan volume (volumetric strain) [8]. Sama halnya ketika suatu timbunan diberikan suatu beban diatasnya, maka dapat terjadi perubahan volume tersebut. Perbandingan antara perubahan volume dengan tekanan hidrostatik yang terjadi pada suatu bahan disebut dengan kompresbilitas,

$$
\begin{gathered}
K=\frac{P V_{0}}{\Delta V} \\
\text { Compressibility }=\frac{1}{k}
\end{gathered}
$$

Uji kompresbilitas yang biasa dilakukan ada beberapa jenis bergantung terhadap kebutuhan seperti pada Gambar 5. Hal ini disebabkan oleh tekanan yang diberikan di bumi ialah beragam, tidak hanya disebabkan oleh 1 arah saja. Oleh karena itu, pada Chiligraian (1992) menjelaskan lebih rinci beberapa jenis dan metodologi untuk mendapatkan kompresbilitas [9].

\section{Gaussian Mean Mixture}

Ketika mendapati suatu distribusi data (eg. Histogram), proses interpretasi yang dapat dilakukan adalah mengetahui bentuk dari distribusi itu sendiri. Tetapi, didalam 1 bentuk distirbusi (Uniform) terdapat beberapa bentuk distribusi lainnya yang disebut dengan multimodal [10]. Hal ini dapat diselesaikan menggunakan metode Gaussian Mean Mixture 

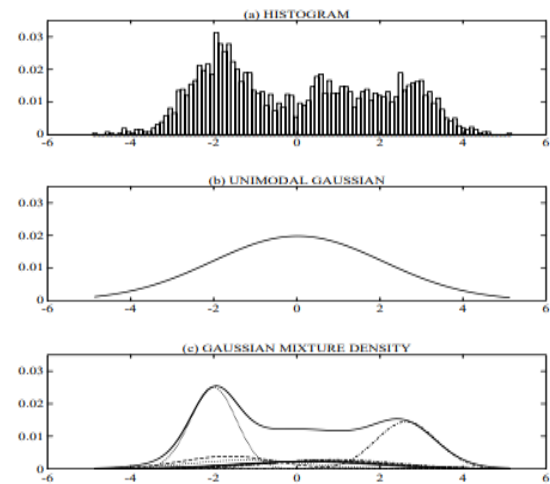

Gambar 6. Distribusi normal (A) Histogram data, (B) Distribusi Gaussian dan (C) Gaussian Mixture Density

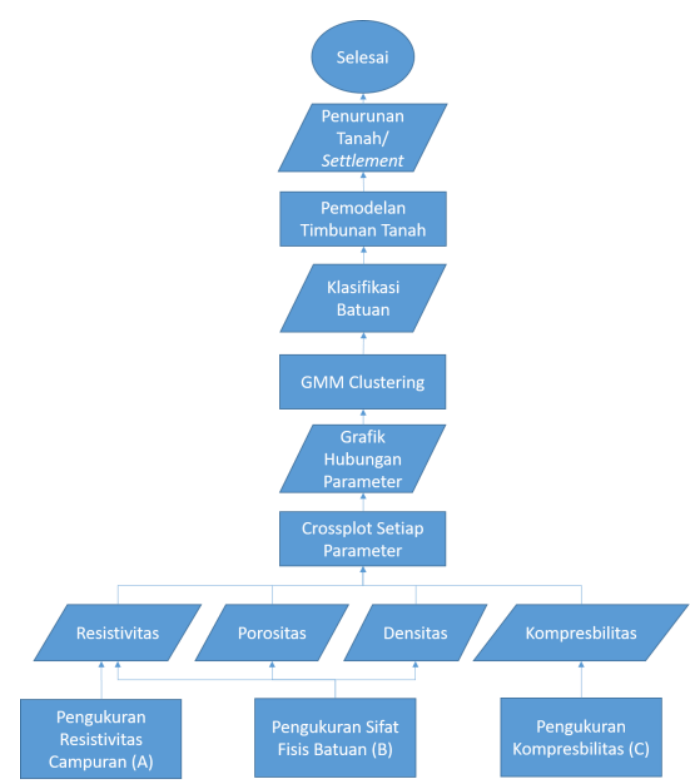

Gambar 7. Skema Kerja Output Akhir Penelitian

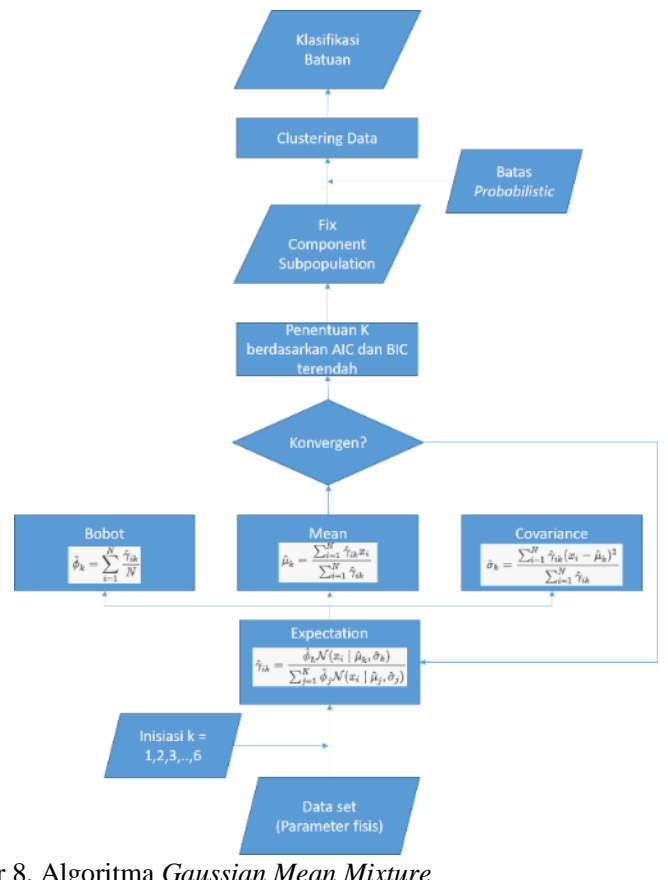

Gambar 8. Algoritma Gaussian Mean Mixture

dimana mendekati sub-distribusi menggunakan bentuk distribusi normal atau Gaussian. Dengan mendapatkan nilai rata rata $(m e a n / \mu)$ dan covariance $(\Sigma)$ pada data maka akan didapatkan bentuk distribusi menggunakan persamaan berikut, $g(x \mid \mu, \Sigma)=\frac{1}{(2 \pi)^{D / 2}|\Sigma|^{1 / 2}} \exp \left\{-\frac{1}{2}(x-\mu)^{\prime}|\Sigma|^{-1}(x-\mu)\right\}$

Penyelesaian dalam Clustering data menggunakan GMM biasanya dilakukan dengan cara Expectation-Maximization (EM) dimana menggunakan inisial model dari parameter GMM dimana digunakan untuk mengestimasi model baru dengan nilai probabilitas yang lebih tinggi [11]. Dari model baru tersebut kemudian dijadikan model inisial untuk iterasi selanjutnya sampai mendapatkan nilai akhir yang konvergen. Distribusi model dapat dilihat pada Gambar 6.

Expectation Step:

$$
G=\frac{w * g(x \mid \mu, \Sigma)}{\sum w * g(x \mid \mu, \Sigma)}
$$

Maximazation Step:

$$
\begin{gathered}
w^{\prime}=\sum \frac{G}{N} \\
\mu^{\prime}=\frac{\sum G x}{\sum G} \\
\sum=\frac{\sum G\left(x-\mu^{\prime}\right)^{2}}{\sum G}
\end{gathered}
$$

\section{Settlement}

Secara umum, penurunan (Settlement) pada tanah yang disebabkan oleh pembebanan dapat dibagi ke dalam dua kelompok besar, yaitu:

1. Penurunan konsolidasi (consolidation Settlement), yang merupakan hasil dari perubahan volume tanah jenuh air sebagai akibat dari keluarnya air yang menempati poripori tanah. Penurunan konsolidasi dibagi menjadi dua, yaitu penurunan konsolidasi primer dan penurunan konsolidasi sekunder.

2. Penurunan segera (immediate Settlement), yang merupakan akibat dari deformasi elastis tanah kering, basah, dan jenuh air tanpa adanya perubahan kadar air.

Perhitungan penurunan segera umumnya didasarkan pada penurunan yang diturunkan dari teori elastisitas. Besarnya penurunan konsolidasi primer untuk lempung yang terkonsolidasi secara normal (normally consolidated) dapat dihitung dengan persamaan:

$$
S=\frac{C c H}{1+e_{0}} \log \left(\frac{P_{0}+\Delta P}{P_{0}}\right)
$$

Dimana settlement $(S)$ diepngaruhi oleh koefisian $\mathrm{C}_{\mathfrak{c}}$, angka pori awal $\mathrm{e}_{0}$, tegangan overburden efektif awal dan perbedaan tengangan di muka tanah $\Delta P$.

\section{METODOLOGI}

\section{A. Alat dan Bahan}

Alat dan bahan yang digunakan dalam penelitian ini adalah 1 set pengukuran skala laboratorium untuk mendapatkan nilai Resistvitias berupa alumunium foil, paralon, multimeter, kabel buaya dan Kompresbilitas berupa Universal Compression and Tension (UCT), neraca digital dan jangka sorong. Sedangkan untuk pembuatan core diperlukan 1 set alat Core dan palu. Untuk pengolahan data digunakan perangkat lunak Minitab, Matlab 2015, Microsoft Word, Excel dan Power Point.

\section{B. Skema Kerja}

Adapun skema kerja pada penilitian ini dibagi menjadi 2, yaitu berupa skema utama pengerjaan dari akuisisi data yang dibutuhkan sampai dengan output utama yang diinginkan 
yang dapat dilihat pada Gambar 7. dan berupa skema algoritma metode Gaussian Mean Mixture untuk mengetahui bagaimana alur pengerjaan script Matlab yang dapat dilihat pada Gambar 8.

Sampel yang diambil adalah batuan karbonat dengan dimensi lebih dari $15 \mathrm{~cm}$ x $15 \mathrm{~cm}$ x $15 \mathrm{~cm}$ agar dapat dilakukan coring. Setelah itu, coring dari batuan karbonat sehingga mendapatkan sampel core kurang lebih dengan dimensi $8 \mathrm{~cm} \times 8 \mathrm{~cm} \times 10 \mathrm{~cm}$ dengan bentuk silinder dan ditimbang beratnya. Kemudian, setiap core dikeringkan dengan cara dimasukan ke dalam oven. Setelah dilakukan pengeringan, dilakukan pemisahan antara core yang kering dengan core yang akan diberikan fluida dan keduanya di timbang beratnya. Pemberian fluida pada core dilakukan dengan menempatkannya di dalam suatu wadah dengan isi fluida dan direndam dengan waktu yang berbeda - beda. Setelah direndam dengan waktu yang berbeda, sampel core diambil dan ditimbang beratnya. Setelah core disiapkan, maka pengukuran parameter fisis batuan. Setelah didapatkan parameter fisis dilakukan perhitungan data statistik untuk mendapatkan distibusi menggunakan Minitab dan Excel. Kemudian, syarat klasifikasi menggunakan GMM adalah histogram memiliki bentuk distribusi multimodal dan memiliki korelasi yang baik (mendekati nilai 1 atau -1) [10]. Dari klasifikasi yang telah didapatkan kemudian dijadikan sebagai input ke dalam perangkat lunak GEOP5-Settlement dan dilakukan analisis Settlement setiap model yang direncanakan.

\section{ANALISIS DATA DAN PEMBAHASAN}

Setelah dilakukan akuisisi data terkait parameter fisis, kemudian dilakukan perhitungan data statistic berupa korelasi setiap parameter yang dapat dilihat pada Tabel 1 . serta distribusi tiap parmaeter yang dapat dilihat pada Gambar 9. maka dapat dilihat distribusi pada histogram. Contohnya adalah pada Gambar 10 sampai Gambar 14, dimana nilai mean densitas adalah 1.903. Pada histogram seharusnya posisi mean terletak pada puncak tertinggi pada histogram parameter tersebut. Tetapi setelah digambar kembali distribusi dari densitas, didapatkan adanya double peak atau yang disebut dengan multimodal yaitu puncak kedua pada nilai kisaran $2.1-2.2$ gram per sentimeter kubik. Bentuk distribusi tersebut juga didapatkan pada distribusi porositas dan kompresibilitas. Sedangkan pada resistivitas didapati bahwa bentuk distribusinya cenderung hanya satu puncak. Selain syarat pengklasifikasian GMM adalah bentuk yang multimodal, syarat selanjutnya adalah memiliki korelasi yang baik (mendekati 1 atau -1). Penentuan jumlah segmen pada metode GMM dapat mengacu pada nilai minimum dari AIC (Akaike Information Criterion) dan BIC (Bayesian Information Criterion). Pada penilitian kali ini dilakukan percobaan jumlah segmen dari 1 sampai dengan 6. Dari segmen - segmen yang telah dilakukan percobaan didapatkan bahwa nilai AIC dan BIC minimum ketika segmen berjumlah 1. Tetapi, hal ini memberikan permasalahan karena pada Gambar 3. (A) menunjukan adanya dua trend yang terpisah. Sehingga, dari segmen memungkinkan adalah 2 sampai dengan 6. Sehingga jumlah segmen optimum berdasarkan nilai AIC dan BIC minimum adalah 2. Metode klasifikasi GMM untuk mendapatkan klasifikasi 3 parameter
Tabel 1.

Korelasi antar parameter fisis

\begin{tabular}{ccccc}
\hline \hline Korelasi & Density & Porosity & Resistivity & Kompresibilitas \\
\hline Density & 1 & -0.759 & 0.176 & -0.544 \\
Porosity & -0.759 & 1 & -0.377 & 0.490 \\
Resistivity & 0.176 & -0.377 & 1 & -0.095 \\
Kompresibilitas & -0.544 & 0.490 & -0.095 & 1 \\
\hline \hline
\end{tabular}

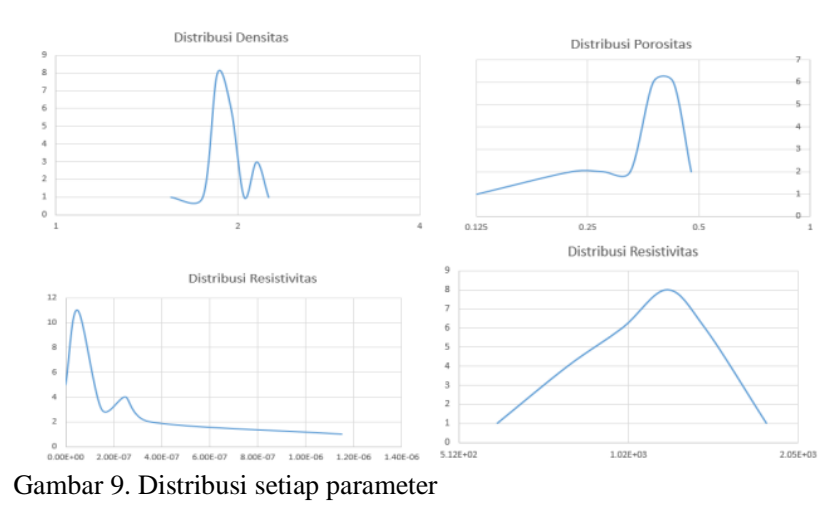

Gambar 9. Distribusi setiap parameter

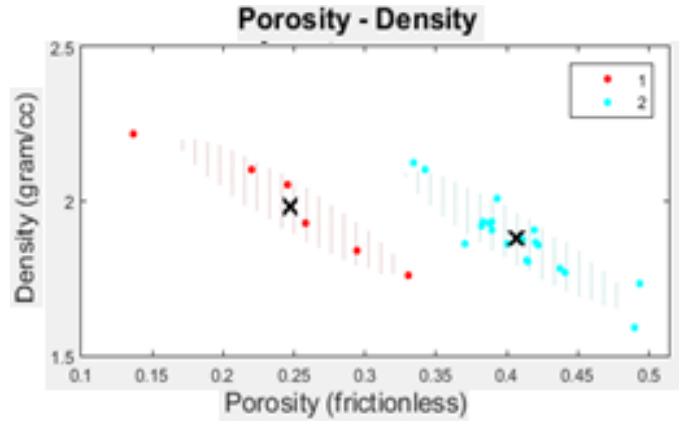

Gambar 10. Hasil klasifikasi GMM pada Porositas-Densitas

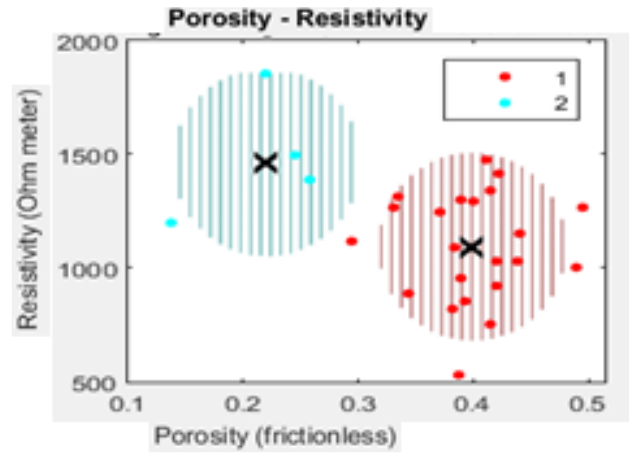

Gambar 11. Hasil klasifikasi GMM pada Porositas - Resistivitas

menggunakan kode Matlab. Untuk penentuan parameter pada sumbu $\mathrm{x}$ dan $\mathrm{y}$ adalah parameter yang terkorelasi dengan baik. Pada sumbu z merupakan parameter yang digunakan sebagai pengklasifikasian lanjutannya. Sehingga, pada penilitian ini sumbu $\mathrm{x}$ dan $\mathrm{y}$ adalalah parameter densitas dan porositas, sedangkan sumbu $\mathrm{z}$ adalah parameter kompresibilitas

Dari hasil klasifikasi dengan 3 parameter yang ditunjukkan pada Gambar 15. menunjukan bahwa batuan dengan nilai kompresibilitas relatif jatuh pada $10^{-7}$ sampai $10^{-8}$. Mengacu pada kondisi pelapukan karbonat [5], kondisi batuan memiliki keadaan pelapukan yang berbeda. Berdasarkan populasi batuan yang lebih keras (kompresibilitas dibawah $10^{-10}$ ) sangat sedikit, hal ini akan berpengaruh pada perhitungan klasifikasi atau posisi segmen yang cenderung mengikuti populasi terbanyak. Sehingga pada pengklasifikasian GMM dipengaruhi oleh proses akuisisi dan jumlah sampel yang digunakan. Semakin banyak sampel 


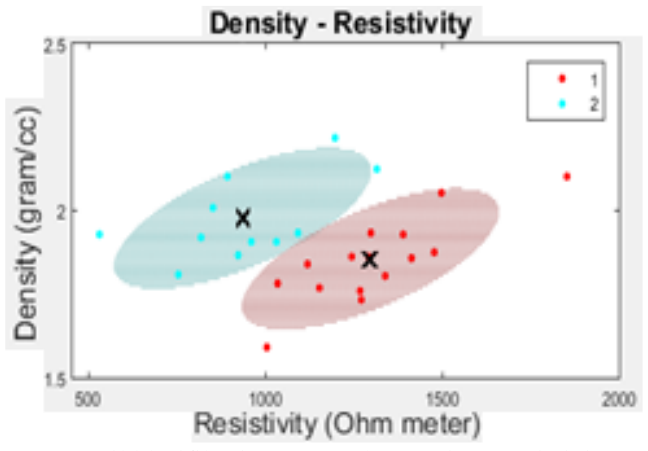

Gambar 12. Hasil klasifikasi GMM pada Densitas-Resistivitas

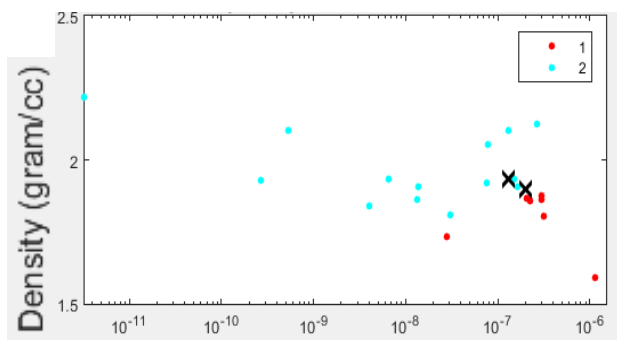

Gambar 13. Hasil klasifikasi GMM pada Densitas-Kompresibilitas

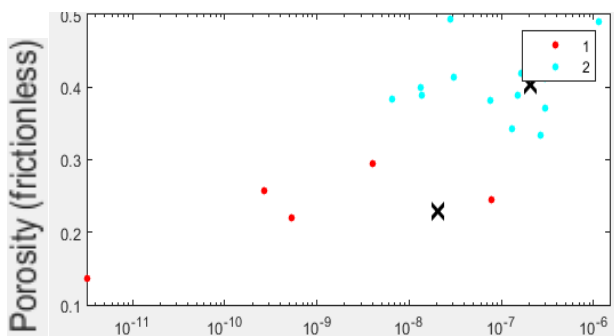

Gambar 14. Hasil klasifikasi GMM Porositas-Kompresibilitas

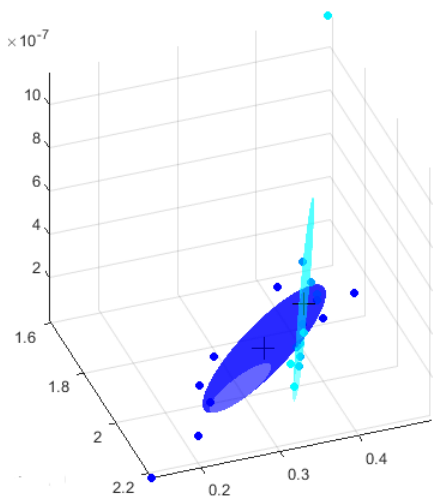

Gambar 15. Klasifikasi Gassian Mixture Model 3 Parameter. X-axis Porosity, Y-axis Density, z-Axis Kompresibilitas

Tabel 2.

Parameter hasil klasfikasi

\begin{tabular}{rrrr}
\hline Klasifikasi- & $\begin{array}{c}\text { Densitas } \\
\text { (gram/cc) }\end{array}$ & Porositas & $\begin{array}{c}\text { Kompresibilitas } \\
(1 / \text { Pascal) }\end{array}$ \\
\hline 1 & 1.921 & 0.346 & $1.0526 \times 10^{-7}$ \\
2 & 1.906 & 0.394 & $2.4846 \times 10^{-7}$ \\
\hline \hline
\end{tabular}

yang digunakan dengan kualitas akusisi data yang baik, akan memberikan pengklasifikasian batuan yang baik dengan korelasi yang tinggi. Sehingga dengan metode Gaussian Mean Mixture dapat mengklasifikasikan batuan untuk kebutuhan geoteknik diklasifikasikan menjadi 2 jenis batuan. Kemudian, dari Tabel 3. dilakukan konversi menjadi parameter geoteknik yang akan digunakan sebagai input pada analisis penurunan tanah (Settlement). Perilaku dalam analisis settlement dapat dilihat pada Tabel 4. Parameter dari
Tabel 3 .

Klasifikasi parameter geoteknik batuan

\begin{tabular}{rrrrrr}
\hline \multicolumn{7}{c}{ Klasifikasi parameter geoteknik batuan } \\
Klasifikasi- & $\begin{array}{c}\text { Specific } \\
\text { Weight } \\
\left(\mathrm{kN} / \mathrm{m}^{3}\right)\end{array}$ & $\begin{array}{c}\text { Edef } \\
(\mathrm{Mpa})\end{array}$ & $\begin{array}{c}\text { Poisson } \\
\text { Ratio }\end{array}$ & Beta & $\begin{array}{c}\text { Eoed } \\
(\mathrm{Mpa})\end{array}$ \\
\hline 1 & 18.838 & 6.932 & 0.243 & 0.844 & 8.210 \\
2 & 18.687 & 3.396 & 0.344 & 0.638 & 5.322 \\
\hline \hline
\end{tabular}

Tabel 4.

Perilaku dalam analisis Settlement

\begin{tabular}{|c|c|c|c|}
\hline Jenis timbunan & Perilaku & Keterangan & Jenis/Nilai \\
\hline Limestone & tanpa batas & Tanah & Clay \\
\hline \multirow[t]{3}{*}{ Klasifikasi 1} & batas & $\begin{array}{l}\text { Berat jenis } \\
\text { tanah }\end{array}$ & $20.5 \mathrm{kN}$ \\
\hline & Pembebana & Koefisien & \\
\hline & $\mathrm{n}$ & Konsolidasi & \\
\hline \multirow[t]{3}{*}{$\begin{array}{c}\text { Limestone } \\
\text { Klasifikasi } 2\end{array}$} & tanpa batas & Tanah & $\begin{array}{c}6.700 \mathrm{E}-03 \\
\mathrm{~m} / \text { day }\end{array}$ \\
\hline & batas & nan & $\begin{array}{c}4.320 \mathrm{E}-03 \\
\mathrm{~m} / \text { day }\end{array}$ \\
\hline & $\begin{array}{c}\text { Pembebana } \\
\mathrm{n}\end{array}$ & $\begin{array}{l}\text { Ketebalan } \\
\text { Timbunan }\end{array}$ & 5 meter \\
\hline $\begin{array}{l}\text { Limestone } \\
\text { Mixing } \\
\text { urutan }\end{array}$ & tanpa batas & $\begin{array}{l}\text { Batas } \\
\text { Incompressi } \\
\text { ble }\end{array}$ & $\begin{array}{l}11 \text { meter dari } \\
\text { permukaan }\end{array}$ \\
\hline \multirow[t]{2}{*}{12} & batas & $\begin{array}{l}\text { Muka air } \\
\text { tanah }\end{array}$ & $\begin{array}{l}2 \text { meter dari } \\
\text { permukaan }\end{array}$ \\
\hline & $\begin{array}{c}\text { Pembebana } \\
n\end{array}$ & Muatan & $1000 \mathrm{kN}$ \\
\hline $\begin{array}{l}\text { Limestone } \\
\text { Mixing }\end{array}$ & $\begin{array}{c}\text { tanpa batas } \\
\text { batas }\end{array}$ & & \\
\hline $\begin{array}{c}\text { urutan } \\
21\end{array}$ & $\begin{array}{c}\text { Pembebana } \\
n\end{array}$ & & \\
\hline
\end{tabular}

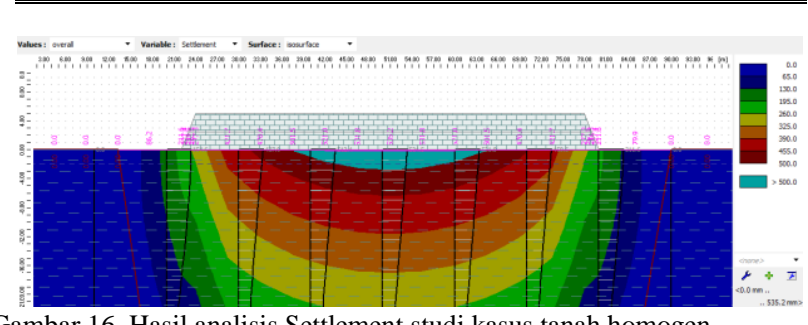

Gambar 16. Hasil analisis Settlement studi kasus tanah homogen

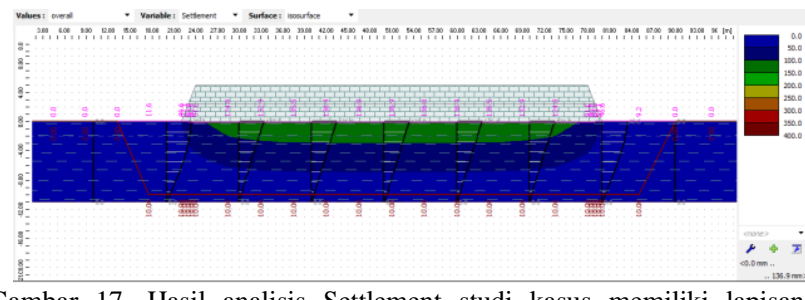

Gambar 17. Hasil analisis Settlement studi kasus memiliki lapisan incompressible

Tabel 2. adalah input yang digunakan dalam pemodelan penurunan tanah. Spesific Weight merupakan besaran geoteknik yang didapatkan dari densitas batuan. Sedangkan Deformation Modulus (Edef) merupakan gradien kekuatan batuan. Nilai Odef memiliki nilai yang berbanding terbalik dengan nilai kompresibilitas. Dengan menggunakan nilai posson ratio yang didapatkan dari uji tekan, maka nilai Oedometric Modulus (Eoed) yang merupakan perbandingan tekanan yang diberikan terhadap perubahan volumenya dapat ditentukan. Pada pemodelan penurunan tanah menggunakan model dengan spesifikasi seperti berikut (untuk koefisien konsolidasi didapatkan dari penilitian tanah di Gresik [12]). Hasil analisis settlement dapat dilihat pada Gambar 16 dan Gambar 17.

Dari analisis yang dilakukan, ketika pemodelan penurunan tanah tidak menggunakan batas/bedrock menghasilkan 


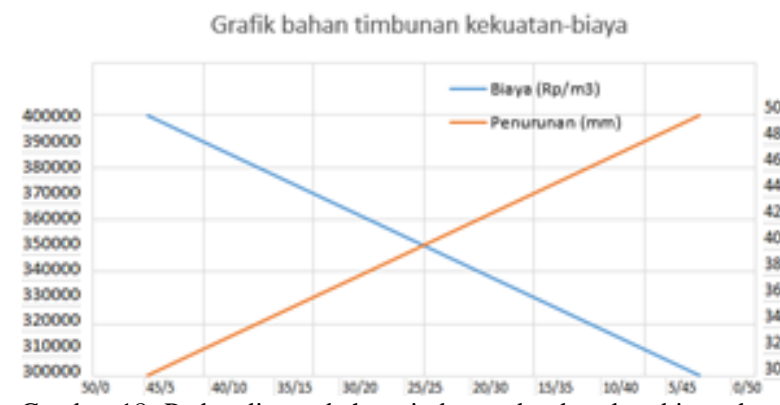

Gambar 18. Perbandingan bahan timbunan berdasarkan biaya dengan penurunan.(x-axis menyatakan Limestone klasifikasi 1:Limestone klasifikasi 2)

Tabel 5 .

Settlement dan konsolidasi dari model homogen (dalam mm)

\begin{tabular}{cccccc}
\hline \hline \multirow{2}{*}{ Waktu } & \multicolumn{2}{c}{ Terhadap Tanah (Homogen) } & & Consoli \\
& Mode & Model & Model & Model & dation \\
& 11 & 2 & $1-2$ & $2-1$ & \\
\hline 1 Minggu & 501.8 & 495.1 & 500.1 & 500.1 & $25 \%$ \\
1 Bulan & 509.1 & 502.3 & 508.9 & 508.9 & $60 \%$ \\
1 Tahun & 531.1 & 524 & 530.1 & 530.1 & $80 \%$ \\
2 Tahun & 532.9 & 525.8 & 531.1 & 531.1 & $90 \%$ \\
3 Tahun & 533.1 & 525.9 & 532.2 & 532.2 & $95 \%$ \\
Overall & 533.1 & 525.9 & 535.2 & 532.2 & $100 \%$ \\
\hline \hline
\end{tabular}

Tabel 6.

Settlement dan konsolidasi dari model dengan batas (dalam mm)

\begin{tabular}{cccccc}
\hline \multicolumn{3}{c}{ Settlement dan konsolidasi dari model dengan batas (dalam mm) } \\
Waktu & \multicolumn{3}{c}{ Terhadad (Ada batas) } & \multicolumn{3}{c}{$\begin{array}{c}\text { Consoli } \\
\text { dation }\end{array}$} \\
& Mode & Model & Model & Model & \\
& 11 & 2 & $1-2$ & $2-1$ & \\
\hline 1 Minggu & 97.2 & 91.6 & 94.2 & 93.8 & $25 \%$ \\
1 Bulan & 104.9 & 98.8 & 101.7 & 101.2 & $60 \%$ \\
1 Tahun & 127.9 & 120.5 & 123.9 & 123.3 & $80 \%$ \\
2 Tahun & 129.9 & 122.3 & 125.8 & 125.2 & $90 \%$ \\
3 Tahun & 130 & 122.4 & 126 & 125.4 & $95 \%$ \\
Overall & 141.5 & 137.5 & 138.4 & 137.8 & $100 \%$ \\
\hline \hline
\end{tabular}

Tabel 7.

Settlement setiap bahan timbunan (dalam mm)

\begin{tabular}{clcll}
\hline \hline Waktu & \multicolumn{2}{c}{ Perbandingan Kekuatan } & & \\
& Model 1 & Model 2 & $\begin{array}{l}\text { Model } \\
\text { (urutan 1 } \\
\text { 2) }\end{array}$ & $\begin{array}{l}\text { Model } \\
\text { (urutan 2 } \\
-1 \text { ) }\end{array}$ \\
\hline Overall & $0.6 \mathrm{~mm}$ & $1 \mathrm{~mm}$ & $0.6 \mathrm{~mm}$ & $1 \mathrm{~mm}$ \\
\hline \hline
\end{tabular}

penurunan tanah sampai dengan $500 \mathrm{~mm}$. Tetapi, pada pemodelan Settlement menggunakan batas (11 meter dari permukaan), memberikan penurunan tanah sampai dengan $100 \mathrm{~mm}$. Hal ini dikarenakan pada bedrock/batas lapisan lunak tidak mengalami penurunan tanah dan menopang perubahan volume lapisan lunak diatasnya [3]. Oleh karena itu, ketebalan sedimen lunak yang mengalami penurunan tanah dan batas bedrock sangatlah penting pada analisis Settlement.

Dari analisis timbunan yang dilakukan, maksimal penurunan dan proses konsolidasi dapat dilihat pada Tabel 5 sampai 7. Dari semua analisis yang dilakukan, model paling baik adalah model Mixing Limestone klasifikasi 1 dan 2. Sedangkan untuk analiis kekuatan timbunan menghasilkan perubahan yang tidak signifikan yaitu kisaran $0.6-1 \mathrm{~mm}$. Perubahan timbunan yang signifikan dimulai dari $1 \mathrm{~cm}$ yang terhitung sebagai kerusakan sangat ringan. Untuk penentuan model terbaik tidak dapat didsasari penurunan atau kekuatan bahan karena perbedaan yang kecil satu dengan lainnya. Tetapi penentuan model terbaik dapat dilakukan asumsi

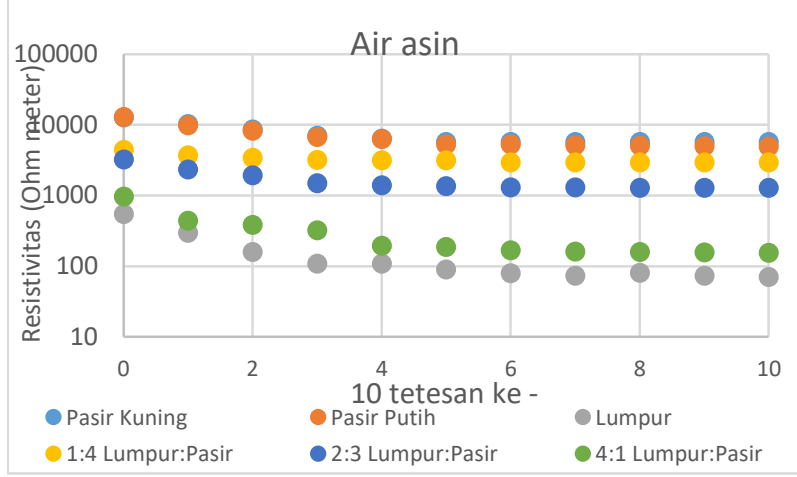

(A)

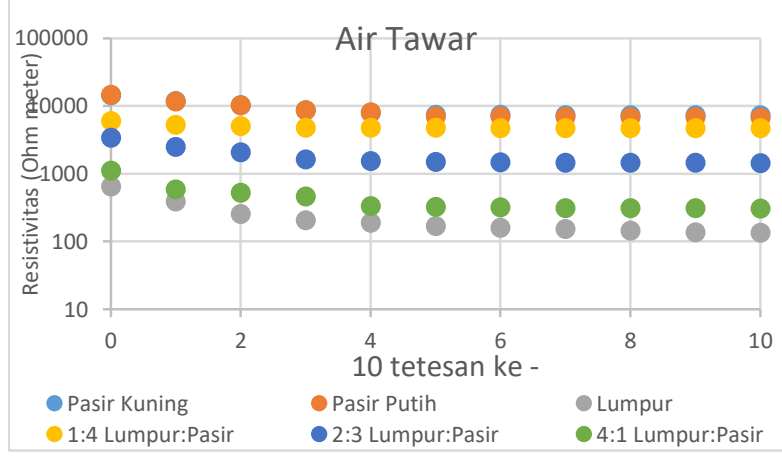

(B)

Gambar 19. Grafik resistivitas campuran terhadap jumlah tetesan

perbedaan harga setiap bahan timbunan berbeda. Contoh harga Limestone klasifikasi 1 (Rp. 80,000 per $\mathrm{m}^{3}$ ) lebih mahal dibandingkan Limestone klasifikasi 2 (Rp. 60,000 per $\mathrm{m}^{3}$ ). Penentuan pemodelan terbaik juga bergantung terhadap biayanya. Contoh studi kasus ketika ingin dilakukan penimbunan sebanyak 50 meter kubik, untuk mendapatkan harga terbaik dengan penurunan paling minimal adalah ketika dilakukan pencampuran dengan urutan timbunan dari paling atas yaitu Limestone klasifikasi 1 dan kemudian diikuti Limestone klasifikasi 2 yang dapat dilihat pada Gambar 18.

Selain itu, pada penilitian ini telah dilakukan pengukuran resistivitas ketika bahan timbunan bertemu dengan lapisan lumpur. Pengukuran resistivitas yang dilakukan bertujuan untuk memberikan perkiraan resistivitas (skala lab) yang akan dikorelasikan terhadap nilai resistivitas pada pengukuran di lapangan. Variasi resistivitas yang dilakukan adalah volume campuran dari bahan timbunan dengan lumpur, perubahan water content berdasarkan banyaknya tetesan yang diberikan dan jenis fluida yang digunakan. Pengukuran resistivitas dimulai dari kondisi kering atau water content sama dengan 0. Gambar 19 menunjukan bahwa semakin banyaknya tetesan air yang diberikan, resistivitas pada campuran akan semakin kecil. Untuk nilai resistivitas menggunakan air asin memiliki perubahan resistivitas lebih besar dibandingkan air tawar dimana pada tetesan ke 100 didapatkan lumpur memiliki resistivitas di bawah $100 \mathrm{Ohm}$ meter. Metode ini dapat diaplikasikan sebagai pembantu dalam interpretasi data geolistrik saat melakukan moniroting timbunan.

\section{KESIMPULAN}

Setelah dilakukan penilitian analisis sifat batuan Karbonat dengan untuk mendapatkan nilai parameter fisisnya serta 
pengaruhnya terhadap penurunan tanah, maka dapat diambil beberapa kesimpulan berupa,

1. Pengklasifikasian batuan karbonat menggunakan Gaussian Mean Mixture menghasilkan 2 kelas dengan kompresibilitas $1.0526 \times 10^{-7}$ per pascal dan $2.484 \times 10^{-7}$ per pascal

2. Pemodelan Penurunan akhir (Overall Settlement) yang optimal adalah model Mixing dengan urutan Limestone klasifikasi 1-klasifikasi 2, yang mengalami penurunan total sebesar $138.4 \mathrm{~mm}$ pada saat konsolidasi $100 \%$.

Adapun saran yang diperlukan untuk meningkatkan kualitas distribusi data dan pengukuran sampel yaitu berupa,

1. Jumlah sampel pengukuran perlu diperbanyak agar mendapatkan distribusi data yang lebih jelas dan lebih baik

2. Pengukuran pada resistivitas tanah dilakukan pada sampel in-situ agar memberikan keadaan riil dengan kondisi kepadatan yang sesuai di lapangan

\section{DAFTAR PUSTAKA}

[1] J. B. Supandjono, Peta Geologi Lembar Surabaya \& Sapulu, Jawa.
Bandung, Indonesia: Pusat Penelitian dan Pengembangan Geologi, 1992.

[2] J. Feld, The Factor of Safety in Soil and Rock Mechanics. New York: Consulting Engineer, 2017.

[3] H. C. Hardiyatmo, Mekanika Tanah I dan II. Gajah Mada University Press, 2002.

[4] J. Schön, Physical Properties of Rocks: A Workbook, vol. 8. Elsevier, 2011.

[5] C. Dubois, J. Deceuster, O. Kaufmann, and M. D. Rowberry, "A new method to quantify carbonate rock weathering," Math. Geosci., vol. 47, no. 8, pp. 889-935, 2015.

[6] A. Q. Arsyadi, K. Yadi, N. Sutra, and R. A. A. Soemitro, "Analisis respon resistivitas sampel tanah TPA Ngipik Kabupaten Gresik berdasarkan uji resistivitas skala laboratorium," J. Tek. ITS, vol. 6, no. 2, pp. D89--D92, 2017.

[7] B. R. Bloss and P. A. Bedrosian, Laboratory Electrical Resistivity Analysis of Geologic Samples from Fort Irwin, California. US Department of the Interior, US Geological Survey, 2018.

[8] Gallgher Corp., "Bulk Modullus Measurment," 2015. [Online]. Available: https://gallaghercorp.com.

[9] R. F. Craig, Mekanika Tanah, 4th ed. Jakarta: Erlangga, 1989.

[10] J. McGonagle, P. Geoff, and V. Tembo, "Gaussian Mean Mixture," 2015. [Online]. Available: https://brilliant.org/wiki/gaussian-mixturemodel/ . [Accessed: 10-Jan-2019].

[11] D. A. Reynolds, "Gaussian mixture models.," Encycl. biometrics, vol. 741, 2009.

[12] D. A. Rahmasari, "Perencanaan Perbaikan Tanah pada Proyek Reklamasi Pantai PT. Wilmar Nabari Gresik - Jawa Timur Dengan Metode Preloading dan Pemasangan Micropile,” 2013. 